\title{
Micro-spectroscopic characterization of organic and hydrous components in weathered Antarctic micrometeorites
}

\author{
A. Suzuki ${ }^{1}$, Y. Yamanoi ${ }^{1}$, T. Nakamura ${ }^{2}$, and S. Nakashima ${ }^{1}$ \\ ${ }^{1}$ Department of Earth and Space Science, Osaka University, 1-1 Machikaneyama, Toyonaka, Osaka 560-0043, Japan \\ ${ }^{2}$ Department of Earth and Planetary Science, Kyushu University, Hakozaki, Fukuoka 812-8581, Japan
}

(Received July 26, 2008; Revised October 31, 2008; Accepted November 3, 2008; Online published February 12, 2010)

\begin{abstract}
Eight unmelted Antarctic micrometeorite (AMMs) recovered from Kuwagata Nunatak were studied on Al-foils by infrared (IR), Raman, and visible reflection micro-spectroscopy in combination with electron microscopy. Major element abundances of the AMMs studied were found to be similar to solar abundance, although all have the common characteristic of $\mathrm{Mg}$-depletion. Absorption bands around $500 \mathrm{~nm}$ were detected for some of the AMMs by the visible micro-spectroscopic method, and these AMMs can be assigned to Fe-hydroxidelike materials. These results suggest that the studied AMMs experienced weathering in Antarctica. Four grains showed the presence of IR $\mathrm{H}_{2} \mathrm{O}$ and $\mathrm{CH}$ bands similar to those of type 2 carbonaceous chondrites, while these were found to be absent in two grains, as in type 3 carbonaceous chondrites. D (disordered: $1360 \mathrm{~cm}^{-1}$ ) and $\mathrm{G}$ (graphite: $1600 \mathrm{~cm}^{-1}$ ) Raman band features of graphitic carbonaceous materials in these AMMs were not similar to those for type 3 but were rather close to those for type 2 and 1 carbonaceous chondrites, although some data showed a degree of deviation. The genetic classification of individual AMM grains can thus be studied by these methods, although the weathering effects and the atmospheric entry heating on organics and hydrous components need to be evaluated. These multiple micro-spectroscopic reflectance methods are useful for the characterization of precious small samples.
\end{abstract}

Key words: Antarctic micrometeorites (AMMs), IR, Raman, visible, micro-spectroscopy, organics, hydrous minerals.

\section{Introduction}

Micrometeorites (size $<1 \mathrm{~mm}$ ) are the major fractions of extraterrestrial materials (Maurette, 2006). The flux of micrometeorites reaching the earth has been determined to be $\sim 40,000$ tons per year by Love and Brownlee (1993), which is two- to threefold higher than that estimated by Grun et al. (1985) or Hughes (1978). Peucker-Ehrenbrink and Ravizza (2000) estimated extraterrestrial matter flux to be $30,000 \pm 15,000$ tons per year based on Os isotopes. In contrast, the total mass flux of meteorites in the mass range from $10 \mathrm{~g}$ to $1 \mathrm{~kg}$ is between 2.9 and 7.3 tons per year (Bland, 2001). It can therefore be concluded that micrometeorites dominate the incoming mass flux of extraterrestrial materials to the earth.

The mineralogical and compositional features of unmelted micrometeorites are reported to be similar to those of hydrous carbonaceous chondrites (Kurat et al., 1994), although the hydrous phases in most micrometeorites are decomposed and dehydrated (Nakamura et al., 2001). In addition, electron energy loss spectroscopic (EELS) analyses have revealed that micrometeorites yield higher concentrations of carbonaceous material (average $\mathrm{C}$ content is 7 wt\%; Engrand and Maurette, 1998) than carbonaceous

Copyright (C) The Society of Geomagnetism and Earth, Planetary and Space Sciences (SGEPSS); The Seismological Society of Japan; The Volcanological Society of Japan; The Geodetic Society of Japan; The Japanese Society for Planetary Sciences; TERRAPUB.

doi:10.5047/eps.2008.11.001 chondrites (average $\mathrm{C}$ content is $\sim 2.5 \mathrm{wt} \%$; Engrand and Maurette, 1998). Carbonaceous chondrites represent only small fraction ( $\sim 3.7 \%$ fall frequency) of all meteorite falls (Grady, 2000) and, consequently, their accretion rates are much lower than those of micrometeorites. Since about $60 \%$ of micrometeorites are classified into the unmelted type (Yada et al., 2004), which can contain about 7 wt $\%$ of carbonaceous materials, 30,000 tons per year micrometeorite flux would deliver about 1,260 tons of carbon (C) per year to the earth. On the other hand, only $3.7 \%$ (carbonaceous chondrite) of 7.3 tons (maximum) per year of meteorite falls can contain about $2.5 \mathrm{wt} \% \mathrm{C}$. This may correspond to about $7 \mathrm{~kg} \mathrm{C}$ per year by meteorites. This is in the same order of magnitude as that estimated by Pasek and Lauretta (2008) (organic C flux from carbonaceous chondirtes is about $0.5 \mathrm{~kg}$ /year). Therefore, extraterrestrial carbonaceous materials are accreting to the earth mainly as micrometeorites $\left(1.3 \times 10^{6} \mathrm{~kg}\right.$ (micrometeorites) vs. 7 or $0.5 \mathrm{~kg}$ (meteorites) $\mathrm{C}$ per year).

Micrometeorites recovered from Antarctica are called Antarctic micrometeorites (AMMs). Many AMMs are composed of fine-grained minerals and interstitial organic material. Currently, only a few studies have been performed to characterize organic materials in AMMs. Aminoisobutyric acid (AIB) and isovaline were identified in AMMs (Brinton et al., 1998). This organic analysis needed 30-35 AMM grains to detect these compounds, and organic natures for individual grains are not known. Micro 
two-step laser mass spectrometry $\left(\mu \mathrm{L}^{2} \mathrm{MS}\right)$ on individual AMM grains identified complex organic molecules, such as polycyclic aromatic hydrocarbons (PAHs) (Clemett et al., 1998). However, this $\mu \mathrm{L}^{2} \mathrm{MS}$ method elevates the temperature of AMM samples for ionization, and organic features in AMMs can be modified.

Antarctic weathering of AMMs has been suggested by major element abundance (Terada et al., 2001). Sephton et al. (2004) reported that the presence and amount of organic matter from carbonaceous chondrites in Antarctica are strongly associated with Antarctic weathering. Therefore, the effects of weathering should also be evaluated together with the characterization of organic components in AMMs.

In the study reported here, we have attempted to characterize organic features of individual AMMs using nondestructive infrared (IR) and Raman micro-spectroscopic methods. Raman spectroscopy has been conducted on carbonaceous chondrites (Raynal, 2003; Matrajt et al., 2004) and interplanetary dust particles (IDPs) (Wopenka, 1988) with the aim of characterizing graphitic macromolecular organics. However, to date, no Raman data have been reported on AMMs. Although transmission infrared (IR) spectra on AMMs have been reported by Osawa et al. (2001), we test the IR transmission-reflection method (Okumura and Nakashima, 2004) in this study in order to be able to use the same sample mounting method on aluminum (Al)-foils for all of the measurements. For evaluating the Antarctic weathering of AMMs, we determined major element abundances using an electron probe micro-analyzer (EPMA), and colored weathering products were analyzed by visible micro-spectroscopy. We also compared the obtained organic features of AMMs with those of carbonaceous chondrites.

\section{Materials and Methods \\ 2.1 Sampling location}

The AMMs used in this study were picked up from Kuwagata nunatak $\left(72^{\circ} 06^{\prime} \mathrm{S}, 35^{\circ} 15^{\prime} \mathrm{E}\right)$ No. 11 point in 1998 (Yada and Kojima, 2000). The area is $2 \mathrm{~km}$ southwest of the most southern nunatak in the Meteorite Ice Field (Yada and Kojima, 2000). A detailed description of the separation procedure is provided by Yada and Kojima (2000).

\subsection{Sample preparation}

More than 50 grains were identified as micrometeorites from the above sample location using a scanning electron microscope (SEM) equipped with energy-dispersive $\mathrm{X}$-ray analyzer (EDX) based on the compositional criteria (Nakamura et al., 2001). The micrometeorites can be classified into three major textural types based on the degree of melting: unmelted type (least-melted), scoriaceous type (partially-melted), and spherules (totally-melted) (Engrand and Maurette, 1998). Typical unmelted micrometeorites comprise mainly fine-grained materials with various amounts/sizes of vesicles (Engrand and Maurette, 1998). The classification of the Kuwagata point 11 samples are all listed in the AMM catalog of Gakushuin University (http://dust.cc.gakushuin.ac.jp/dust/index.html). The SEM image in this catalog for one of the AMM grains is shown in Fig. 1 (sample name: Y98K11KS020). In order to study

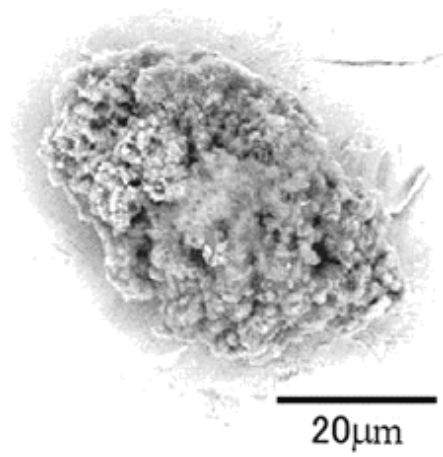

Fig. 1. The secondary electron image of an Antarctic micrometeorite (AMM) sample No. Y98K11KS020 by scanning electron microscopy (SEM). The scale bar is $20 \mu \mathrm{m}$.

Table 1. Description of Antarctic micrometeorite samples.

\begin{tabular}{ccc}
\hline Sample & Type & $\begin{array}{c}\text { Size } \\
\mu \mathrm{m} \times \mu \mathrm{m}\end{array}$ \\
\hline Y98K11KS004 & Unmelted & $150 \times 30$ \\
Y98K11KS010 & Unmelted & $110 \times 20$ \\
Y98K11KS020 & Unmelted & $66 \times 21$ \\
Y98K11KS023 & Unmelted & $90 \times 18$ \\
Y98K11KS026 & Unmelted & $71 \times 12$ \\
Y98K11KS037 & Unmelted & $93 \times 14$ \\
Y98K11KS077 & Unmelted & $95 \times 20$ \\
Y98K11KS093 & Unmelted & $81 \times 42$ \\
\hline
\end{tabular}

organic and hydrous components in AMMs, our aim was to investigate the unmelted type micrometeorites from the Kuwagata point 11 samples. Only eight unmelted AMM grains were left available for this study, which have not been treated by other analyses (Table 1).

Each of eight AMM grains was gently pressed between two Al-foils in order to embed the grains in the Al-foils. Four AMM grains remained on the Al-foils, while the other four AMM grains were separated into two particles on two Al-foils. Successful IR and Raman spectra were obtained on only 11 particles among the above 12 . Four AMM grains and two separated particles from one grain were successfully measured by visible micro-spectroscopy.

For EPMA analysis, AMM particles on the Al-foils were fixed with petropoxi resin and polished with 1- $\mu \mathrm{m} \mathrm{Al}_{2} \mathrm{O}_{3}$ compound to make flat surfaces. Seven particles were successfully measured by EPMA.

\subsection{IR spectroscopy}

IR micro-spectroscopy was conducted directly on the AMMs embedded in the Al-foils. We used here the transmission-reflection method on the Al-foils (Okumura and Nakashima, 2004) in which the IR light was first transmitted into the sample grain, which was approximately $12 \mu \mathrm{m}$ thick, reflected onto the surface of the Al-foils, and again transmitted through the sample. The resulting spectra have absorption features of the sample with twice the thickness without too much reflection artifacts on the grain surface, except for the strong absorption bands, such as silicates. This method enables weak absorption peaks, such as 
aliphatic $\mathrm{CH}$, to be better observed.

For IR measurements, a Fourier transform infrared micro-spectrometer (micro-FTIR), model JASCO FTIR $620+$ IRT30 was used. A ceramic infrared light source, MCT $(\mathrm{HgCdTe})$ detector and a $\times 16$ Cassegrainian mirror were used in the micro-FTIR. The interferometer scan speed is $10 \mathrm{~cm} / \mathrm{s}$, yielding a wavenumber resolution of $4 \mathrm{~cm}^{-1}$. One hundred scans were accumulated for each resultant spectrum. The background spectra were collected on each Al-foil at room temperature. Transmission-reflection spectra at room temperature in the range $4,000-750 \mathrm{~cm}^{-1}$ were collected on these AMMs on Al-foils with a $400 \times 400-$ $\mu \mathrm{m}^{2}$ aperture to cover the whole grain of the AMMs. Small fragments of carbonaceous chondrites (Ivuna, Orgueil, Tagish Lake, Murchison, Murray, Allende, Moss) pressed on Al-foils were also measured by the transmission-reflection method with a $100 \times 100-\mu \mathrm{m}^{2}$ aperture.

\subsection{Raman spectroscopy}

The Raman spectra of both the unmelted AMMs and the Moss CO3 carbonaceous chondrites were measured using a visible-Raman micro-spectrometer (Yamanoi et al., 2004). For measuring Raman spectra, the sample is excited by a 514.5-nm Ar laser. In our study, the laser's intensity was set about $0.2 \mathrm{~mW}$ at the sample surface to avoid its overheating. A Raman spectrum of the sample was measured with a duplicate accumulation of signals at an exposure time of $100 \mathrm{~s}$. The effective wavenumber region is from 100 to $2100 \mathrm{~cm}^{-1}$. The sharp spike peaks often found in Raman spectra due to cosmic rays were then removed from the spectra. The wavenumber resolution is about $2 \mathrm{~cm}^{-1}$. A $\times 20$ long-working distance objective lens was used, giving a spot size of about $5 \mu \mathrm{m} \phi$.

We analyzed five to ten points for each unmelted AMM sample. In total, 73 points of eight unmelted AMMs were measured for Raman spectra under a Laser Raman microscope. The Moss meteorite was measured by the same method as that used for the AMMs. The small fragment of Moss meteorite was pressed between two Al-foils, and two positions were measured for Raman spectra.

\subsection{Visible spectroscopy}

Measurements of visible reflectance spectra were performed by visible micro-spectroscopy (Yamanoi et al., 2009), which is composed of a visible-Raman microspectrometer (Yamanoi et al., 2004) with a dark field objective. The effective wavelength region is from 400 to $800 \mathrm{~nm}$. The wavelength resolution is about $0.5 \mathrm{~nm}$. A $\times 20$ dark field objective lens was used, giving a spot size of about $50 \mu \mathrm{m} \phi$.

A dark spectrum was measured by closing the CCD detector shutter; this dark spectrum was subtracted from all the spectra to remove CCD counts by a dark current. Dark field reflection intensity at $400-800 \mathrm{~nm}$ (reflection spectrum) of the samples on Al-foils was obtained with a duplicate accumulation of signals at an exposure time of $1 \mathrm{~s}$ with an unexposed interval of $1 \mathrm{~s}$. Reflectance spectra of the sample were calculated by dividing the reflection spectra of the samples by those of the white reference (Yamanoi et al., 2009). Amorphous silicon dioxide powders (Kanto Chemical Co.) were used as the white reference material.

One to three positions of each of six AMM particles on Al-foils were measured by visible micro-spectroscopy. Three carbonaceous chondrites (Ivuna CI1, Murchison CM2, and Allende CV3) were also pressed on Al-foils, and three to seven points were measured by visible microspectroscopy.

\subsection{Electron probe micro-analyzer}

The elemental abundance of the polished surfaces of AMM particles were measured by EPMA (JEOL JXA-733 and -733 superprobe). Quantitative analyses with wavelength dispersive $\mathrm{X}$-ray spectrometer were performed at $15 \mathrm{kV}$ of accelerating voltage and a 9- or 10-nA electron beam current with a defocused beam of $20 \mu \mathrm{m}$ in diameter.

\section{Results}

\subsection{Weathering effects}

3.1.1 EPMA analysis Two to 19 points on each AMM were measured by EPMA and averaged. The elemental abundance of AMMs normalized to Si and solar abundance (Anders and Grevesse, 1989) is summarized in Fig. 2(a). The $\mathrm{Al}$ abundance is removed from the diagram because $\mathrm{Al}$-foils and $\mathrm{Al}_{2} \mathrm{O}_{3}$ compounds were used for holding and polishing the samples, respectively. The Ti contents of AMMs are around the detection limit and will not be discussed here.

Y98K11KS010 was found to be phosphorus (P)-enriched compared with the solar abundance, Y98K11KS020-1 to be P- and iron (Fe)-enriched, while Y98K11KS093-1 was found to be potassium (K)-depleted, manganese (Mn)enriched and Fe-depleted. Except for these anomalies, the chemical compositions of AMMs were found to be basically similar to one another. These characteristics of elemental compositions are similar to those for AMMs reported in Wright et al. (1997). Compared with the abundance patterns reported in Kurat et al. (1994), our data resemble those of the phyllosilicate micrometeorites (Fig. 2(a)). SEM observations of our AMM samples revealed fine-grained textures. This and the similarity in elemental abundance suggest that most of our AMM samples might be phyllosilicate-type micrometeorites. Phyllosilicates can be decomposed and dehydrated during atmospheric entry (Nakamura et al., 2001). However, they can also be formed by Antarctic weathering (Noguchi et al., 1999).

The abundances of major and minor elements of carbonaceous chondrites are summarized in Fig. 2(b). In these chondrites, magnesium $(\mathrm{Mg})$ was found to be generally more depleted from the solar abundance than from the carbonaceous chondrites. $\mathrm{K}$ was found to be more enriched than the CM2 and CR2 carbonaceous chondrites, except for Y98K11KS093-1. Nickel (Ni) was significantly depleted from the solar abundance. Other elemental abundances were found to be similar to those found in either type 2 or type 3 chondrites (CM2, CR2, CV3, CO3 chondrite data from McSween and Richardson, 1977; Tagish Lake data from Greshake et al., 2005).

Atomic ratios of three major elements $\mathrm{Si}, \mathrm{Mg}$ and $\mathrm{Fe}$ in AMMs are shown in Fig. 3(a). The AMM data are plotted in a relatively narrow compositional field that includes both low-calcium $(\mathrm{Ca})$ pyroxene and olivine solid solutions (Fig. 3(a)). Compared with AMMs reported previously 

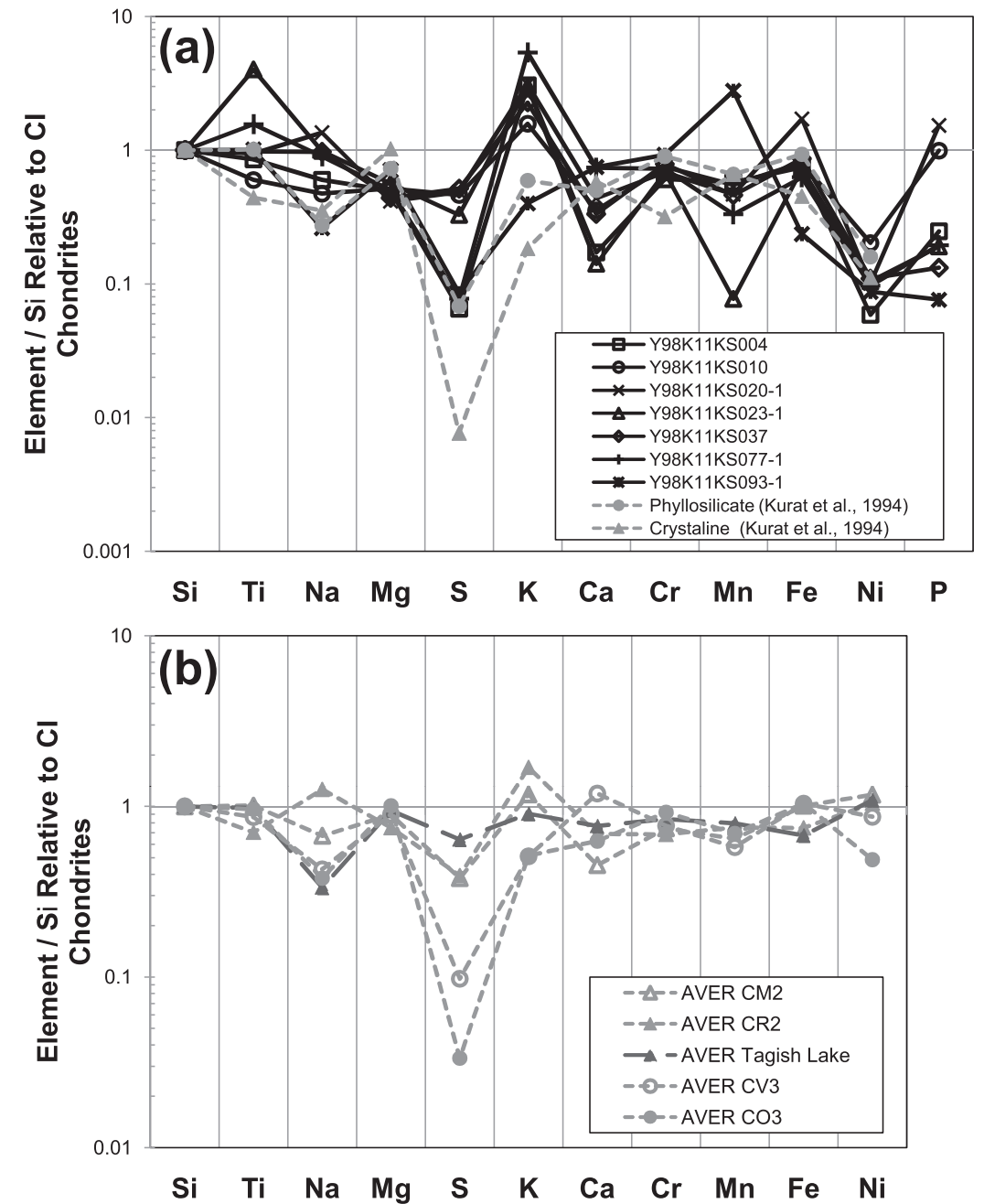

Fig. 2. (a) Elemental abundance diagram (normalized to Si and CI chondrites; Anders and Grevesse, 1989) of Antarctic micrometeorites (AMMs) compared with average data on phyllosilicate and crystalline types AMMs (Kurat et al., 1994). Ti is around detection limit. (b) Average elemental abundance diagram (normalized to Si and CI chondrites) of CM2, CR2, CV3, CO3 (McSween and Richardson, 1977) and Tagish Lake (Greshake et al., 2005).

(Kurat et al., 1994; Genge et al., 1997; Gounelle et al., 2005) (Fig. 3(b)), our AMMs are apparently depleted in $\mathrm{Mg}$ (Fig. 3(a)). The same Mg depletion for the studied AMMs is also observed in Fig. 3(a) with lower $\mathrm{Mg} /(\mathrm{Si}+\mathrm{Fe})$ ratios than those for the $\mathrm{C} 1$ (CI1), C2 (CM2, CR2 and Tagish Lake), $\mathrm{C} 3$ (CO3 and CV3) chondrites (C1, C2, C3 carbonaceous chondrites data from McSween and Richardson, 1977; Zolensky et al., 1993; Tagish Lake data from Greshake et al., 2005).

These elemental abundances of AMMs reveal $\mathrm{Mg}$ depletion, especially for Y98K11KS004, Y98K11KS0201, and Y98K11KS037 (Fig. 2(a) and Fig. 3(a)).

3.1.2 Visible spectroscopy The visible reflectance spectra of five AMMs are shown in Fig. 4. Carbonaceous materials generally absorb a shorter wavelength than the visible range (ultraviolet region) resulting in a yellowbrownish color (Stevenson, 1994). A weak absorption band around $500 \mathrm{~nm}$ was recognized for Y98K11KS004, Y98K11KS010, Y98K11KS020-2, and Y98K11KS037 (Fig. 4). This 500-nm band can be mainly due to electron pair transitions of $\mathrm{Fe}^{3+}$ in goethite or ferrihydrite structures (Scheinost et al., 1998) among ligand field and elec- tron pair transitions of $\mathrm{Fe}^{3+}$ (Sherman and Waite, 1985). In fact, ferrihydrite has been reported in AMMs by Matrajt $e t$ al. (2001). However, Osawa et al. (2003) and Nakamura et al. (2001) did not detect goethite or other iron hydroxides by synchrotron X-ray diffraction. Therefore, the $\mathrm{Fe}^{3+}$ bearing-hydroxide-like materials may have an amorphous nature with relatively low crystalinity (Nagano et al., 2002).

On the other hand, the 500-nm band of iron-hydroxidelike materials cannot be recognized in visible reflectance spectra of Ivuna (C1), Murchison (C2) and Allende (C3) carbonaceous chondrites (Table 3 ).

\subsection{IR spectroscopy}

IR spectra for the AMMs were measured here with the transmission-reflection method. All of the IR spectra of AMMs are shown in Fig. 5(a). Almost all of the spectra show the following absorption bands in common at 3,400 , $2,960,2,925,2,850$, and $1,630 \mathrm{~cm}^{-1}$. However, the strong absorptions around $1,000 \mathrm{~cm}^{-1}$ due to Si-O stretching of silicates show reflection artifacts. Osawa et al. (2001) already reported IR spectra of some AMMs by the transmission method on diamond plates. Their IR spectra are better resolved for silicate bands, which can also be saturated for 


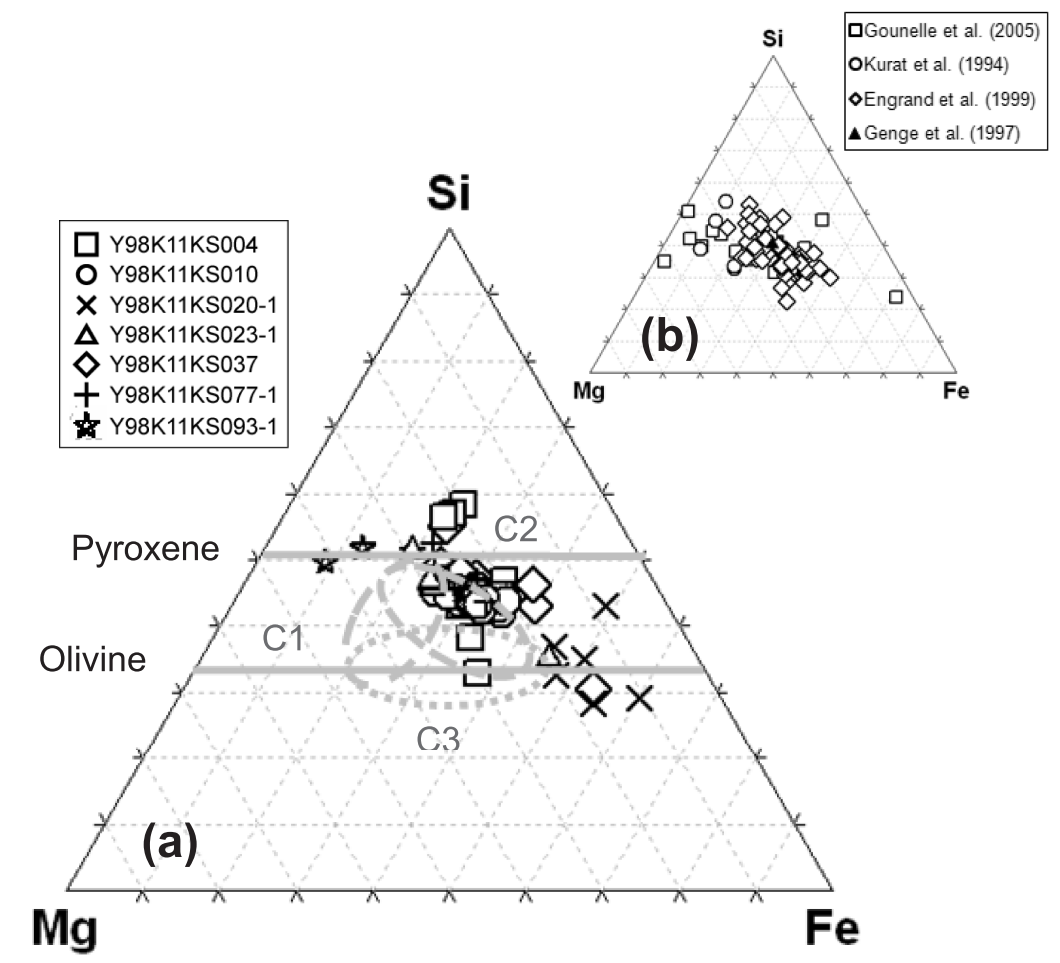

Fig. 3. (a) Ternary Si-Fe-Mg diagram showing the composition of several different points in 7 Antarctic micrometeorite grains (AMMs) investigated in this work. Olivine and pyroxene are represented by gray lines. Dotted and dashed circles are ranges for each group of carbonaceous chondrites (C1 (CI1), C2 (CM2, CR2 and Tagish Lake), C3 (CO3 and CV3). CI1, CM2, CR2, CO3 and CV3 data from McSween and Richardson (1977) and Zolensky et al. (1993). Tagish Lake data from Greshake et al. (2005)). (b) Ternary Si-Fe-Mg diagram of other AMM data from Kurat et al. (1994), Engrand et al. (1999), Genge et al. (1997) and Gounelle et al. (2005).

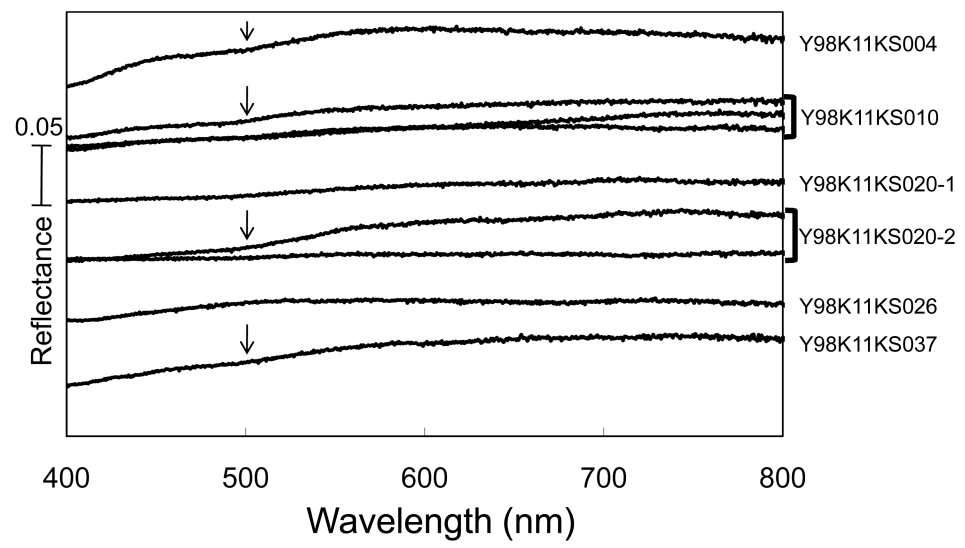

Fig. 4. Visible reflectance spectra of 5 Antarctic micrometeorite grains (AMMs). The Y98K11KS020 grain was separated into two particles on two Al foils (-1 and -2). Two locations on the Y98K11KS020-2 particle and three positions on the Y98K11KS010 grain were analyzed under the dark-field visible microspectrometer.

thick samples. The present transmission-reflection method on Al-foils is useful for organic and hydrous IR features, but not for silicates.

For most of the AMM particles, the features of absorption bands of molecular water are found at $3,400 \mathrm{~cm}^{-1}$ and 1,630 $\mathrm{cm}^{-1}$ (Aines and Rossman, 1984). The $3,400 \mathrm{~cm}^{-1}$ band is observed for all the AMMs, except for Y98K11KS004 and Y98K11KS093-1, 2 (Fig. 5(a)). Three peaks are often found in the $2,800-3,000 \mathrm{~cm}^{-1}$ region, corresponding to aliphatic hydrocarbon stretching features. The peaks at 2,925 and $2,850 \mathrm{~cm}^{-1}$ correspond to the asymmetrical and symmetrical stretching vibrations of
$\mathrm{CH}_{2}$, respectively, while the peak at $2,960 \mathrm{~cm}^{-1}$ corresponds to the asymmetrical stretching vibrations of $\mathrm{CH}_{3}$ in aliphatic hydrocarbons (D'Hendecourt and Allamandola, 1986; Flynn et al., 2001). These $\mathrm{CH}$ peaks were recognized for Y98K11KS0010, Y98K11KS020-1, Y98K11KS037, and Y98K11KS077-1, 2 (Fig. 5(a)). The $\mathrm{CH}$ bending vibrations of these aliphatic hydrocarbons appear as very weak peaks around $1,465 \mathrm{~cm}^{-1}$.

\subsection{Raman spectroscopy}

A representative Raman spectrum for each AMM particle is shown in Fig. 6(a). Twenty of 73 Raman spectra of the AMMs showed a peak around $700 \mathrm{~cm}^{-1}$. This peak can 

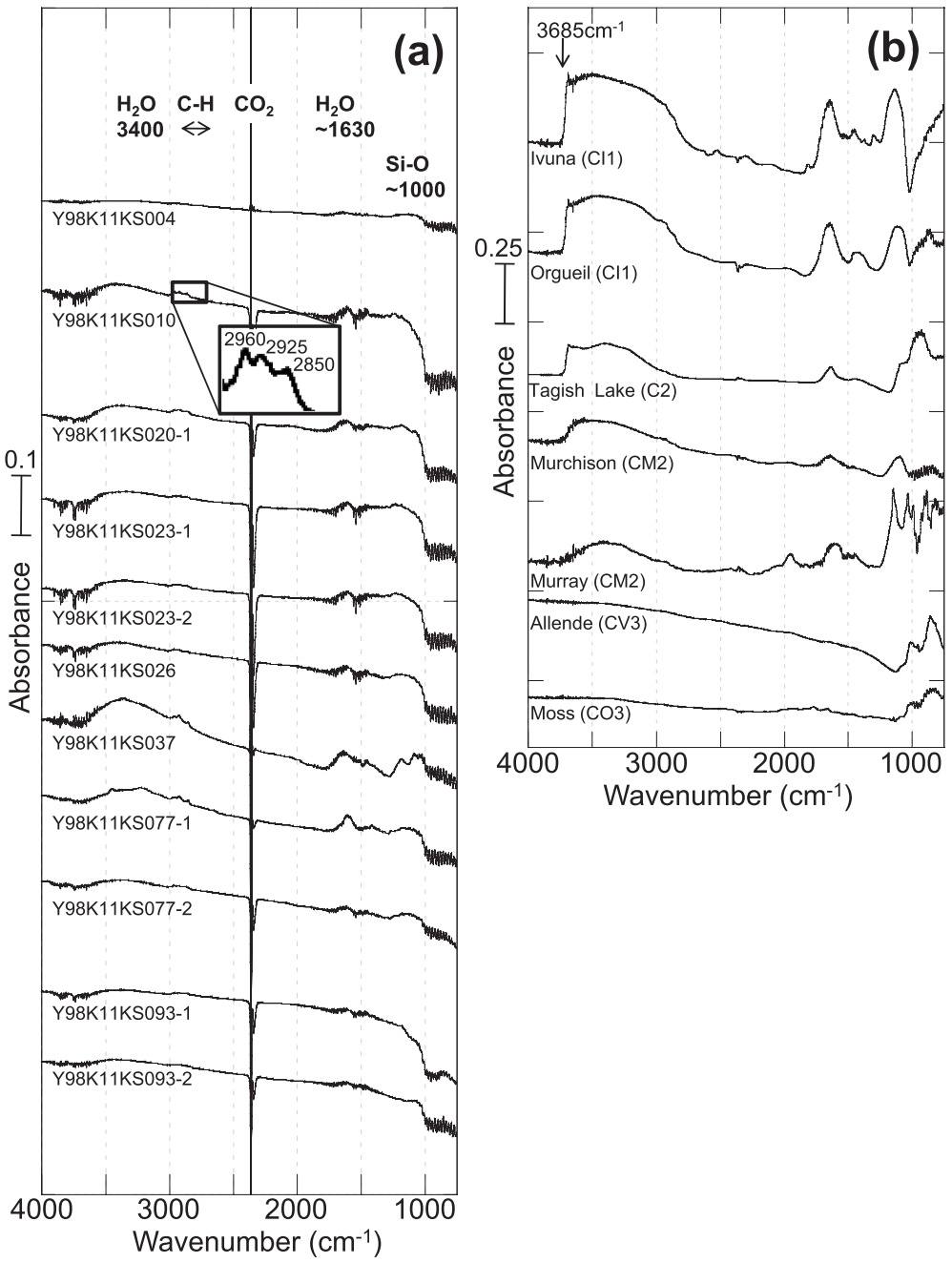

Fig. 5. (a) Infrared (IR) transmission-reflection spectra of 11 Antarctic micrometeorite particles with an aperture of $400 \times 400 \mu \mathrm{m}$ area under the IR micro-spectrometer. (b) IR transmission-reflection spectra of carbonaceous chondrites with an aperture of $100 \times 100 \mu \mathrm{m}$ area under the IR micro-spectrometer.

be due to iron oxides, such as hematite (Amri et al., 2005) or ferrite (Graves et al., 1988). In fact, coarse-grained (5$20 \mu \mathrm{m}$ across) $\mathrm{Fe}$ oxides have been previously reported in AMMs (Noguchi and Nakamura, 2000).

In this study, two major Raman bands around 1,360 and $1,600 \mathrm{~cm}^{-1}$ were observed for all the AMMs together with Moss carbonaceous chondrite. These two bands have also been reported in carbonaceous chondrites (CI1, CM2, CR2, Tagish Lake, CV3: Cronin et al., 1988; Raynal, 2003; Matrajt et al., 2004). These Raman bands are assigned as D (disordered) and G (graphite) bands of aromatic carbon, respectively (Fig. 6(b)). The $\mathrm{G}$ band $\left(1,600 \mathrm{~cm}^{-1}\right.$ ) is due to graphite-like $\mathrm{sp}^{2}$ carbon bonds, while the $\mathrm{D}$ band $\left(1,360 \mathrm{~cm}^{-1}\right)$ is from disorderd $\mathrm{sp}^{3}$ carbons (Ferrari and Robertson, 2000). Although the D band originates from the diamond-like structure of $\mathrm{C}$, diamond has been reported to be present only in trace amounts as nano-particles in meteorites and micrometeorites (Dai et al., 2002). Instead, the $\mathrm{D}$ band often indicates disordered natures of amorphous graphitic carbonaceous materials (Wopenka and Pasteris, 1993; Ferrari and Robertson, 2000), which are major $\mathrm{C}$ forms in cosmic materials (Ehrenfreund et al., 2002). Therefore, in our study, the D band corresponds primarily to "disordered" nature of graphite.

The Raman spectra exhibited significant fluorescence emissions as evidenced by the increasing background intensity toward the higher frequency (larger Raman shift). After a linear baseline correction from 1,000 to $2,000 \mathrm{~cm}^{-1}$, the Raman spectra were fitted by two Lorentzian bands, with the aim of extracting individual band parameters (peak position, full width at half maximum (FWHM), peak intensity, and band area; Fig. 6(b)), as described in Raynal (2003). The obtained values of peak position and FWHM of the G band are plotted in Fig. 7(a), and the peak positions and FWHMs of the D bands are shown in Fig. 7(b). The peak intensity ratio of $\mathrm{D}$ band $\left(I_{\mathrm{D}}\right)$ to that of $\mathrm{G}$ band $\left(I_{\mathrm{G}}\right)\left(I_{\mathrm{D}} / I_{\mathrm{G}}\right)$ and the band area ratio of $\mathrm{D}$ band to the sum of $\mathrm{D}$ and $\mathrm{G}$ bands $\left(A_{\mathrm{D}} / A_{(\mathrm{D}+\mathrm{G})}\right)(\%)$ are presented in Fig. $7(\mathrm{c})$. These parameters indicate the degrees of structural organization (ordering) of terrestrial carbonaceous material (Wopenka and Pasteris, 1993). With increasing ordering, the FWHM of the $G$ and $D$ bands can be seen to become narrower and the peak position (frequency) of the $G$ bands to become larger. These bands have already been reported for insoluble organic matter from carbonaceous chondrites (Busemann et al., 2007) and used as an indicator of thermal meta- 

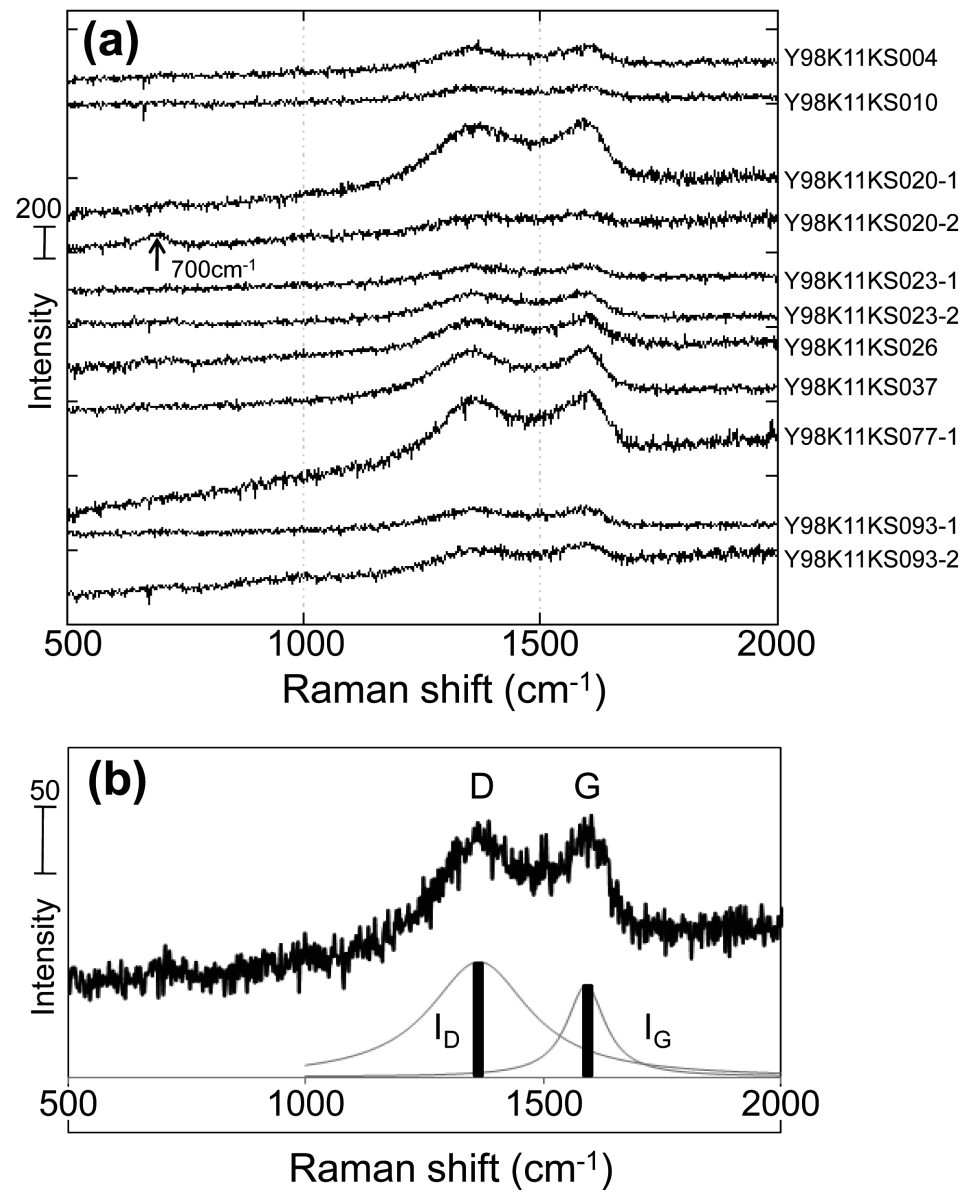

Fig. 6. (a) Representative Raman spectra for different positions of about $1 \mu \mathrm{m}$ spot size under the Raman micro-spectrometer in 8 Antarctic micrometeorite grains. (b) A representative Raman band fitting with 2 Lorentzian bands to obtain peak positions, peak heights $\left(I_{\mathrm{D}}, I_{\mathrm{G}}\right)$, band areas $\left(A_{\mathrm{D}}, A_{\mathrm{G}}\right)$ and full width at half maximum (FWHM) for D (disordered: $1360 \mathrm{~cm}^{-1}$ ) and $\mathrm{G}$ (graphite: $1600 \mathrm{~cm}^{-1}$ ) bands (sample: Y98K11KS010).

morphism of carbonaceous chondrites (Bonal et al., 2006).

The peak position and the FWHM of the G band of the AMMs range from 1,582 to $1,595 \mathrm{~cm}^{-1}$ and from 81 to $133 \mathrm{~cm}^{-1}$, respectively (Fig. 7(a)). The peak position and the FWHM of the D band for the AMMs range from 1,357 to $1,373 \mathrm{~cm}^{-1}$ and from 166 to $265 \mathrm{~cm}^{-1}$, respectively (Fig. 7(b)). The $I_{\mathrm{D}} / I_{\mathrm{G}}$ and $A_{\mathrm{D}} / A_{(\mathrm{D}+\mathrm{G})}(\%)$ range from 1.1 to 1.6 and from 65 to 78 , respectively (Fig. 7(c)). These data are summarized in Table 2.

\section{Discussion}

Within the framework of discussing the characteristics of organic components in AMMs, we will first evaluate their weathering after falling into Antarctic ice sheets, based on elemental composition and the visible micro-spectroscopy. Organic features in the IR and Raman spectra of AMMs will then be discussed and compared with those in carbonaceous chondrites.

\subsection{Weathering in Antarctic ice sheets}

The EPMA analyses revealed that major element abundances of our AMMs are mostly similar to those for micrometeorites reported previously (Kurat et al., 1994; Genge et al., 1997; Gounelle et al., 2005)—with the exception of $\mathrm{Mg}$ abundance (Fig. 3(b)). Although relative to carbonaceous chondrites, AMMs are $\mathrm{K}$-enriched and $\mathrm{Mg}$ - and Ni-depleted, the abundance of major and minor elements in AMMs grains is relatively similar to the average abundance patterns of carbonaceous chondrites (McSween and Richardson, 1977; Greshake et al., 2005) (Fig. 2(b)). Kurat et al. (1992a, b) suggested that the K enrichment of AMMs is likely to be of terrestrial atmospheric origin. The origin of the Ni depletion in AMMs is not yet understood due to conflicting explanations provided by earlier researchers (Presper et al., 1993; Brownlee et al., 1997), or it is due to atmospheric entry (Badjukov and Raitala, 2003).

Terada et al. (2001) found a correlation between the $\mathrm{Mg} /$ silicon ( $\mathrm{Si}$ ) ratio (SEM-EDS peak height ratio) at the surface of the unmelted AMM samples and the age of ice in which the AMMs are embedded. The $\mathrm{Mg} / \mathrm{Si}$ ratio of samples which were taken from the same point as our AMMs (Kuwagata point No. 11) is reported to be $0.43 \pm 0.14$ (Terada et al., 2001). Based on the $\mathrm{Mg} / \mathrm{Si}$ ratio vs. age of ice sheets (Terada et al., 2001), this sample is supposed to have been buried in Antarctic ice for about 30,000 years, which is consistent with the ice core age (Terada et al., 2001). Therefore, the $\mathrm{Mg}$ depletion found in our AMMs can be explained by weathering in the Antarctic ice for a relatively long period and, therefore, can be taken as an indicator of Antarctic weathering (Table 3).

The visible reflectance spectra of AMMs showed a weak broad absorption band around $500 \mathrm{~nm}$ which can be due to Fe-hydroxide-like materials (Fig. 4). On the other hand, 

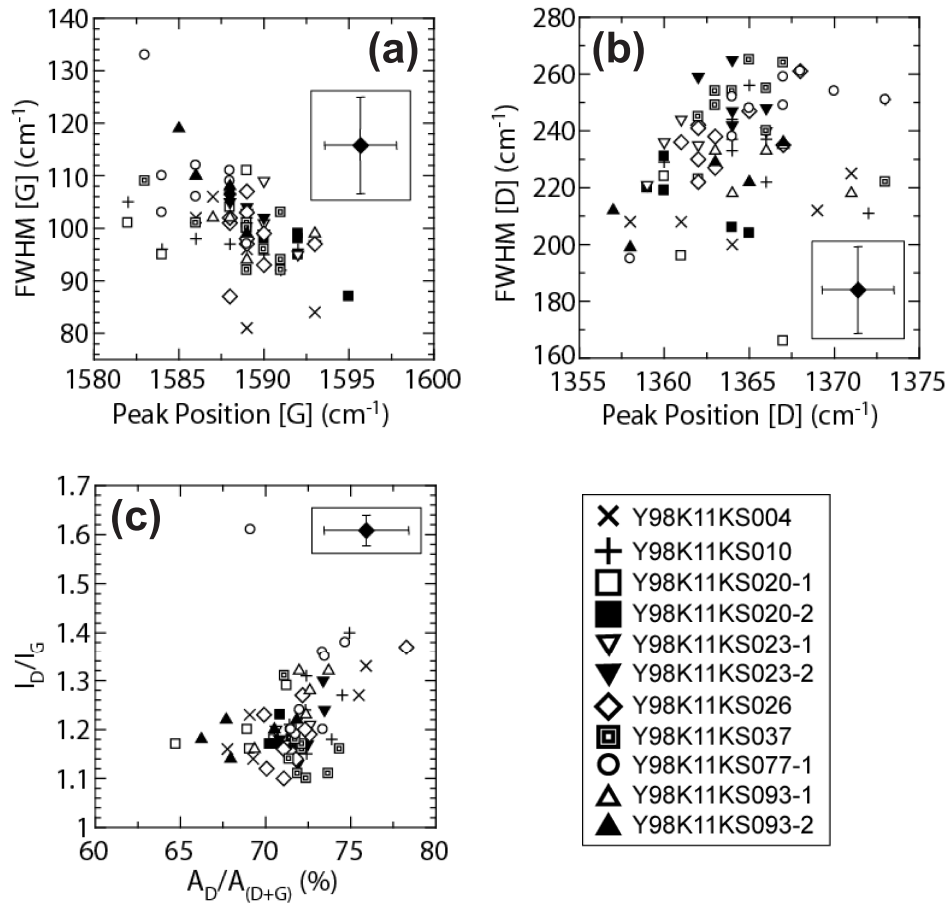

Fig. 7. The correlation diagrams of Raman parameters for $\mathrm{G}$ and $\mathrm{D}$ bands of the Antarctic micrometeorites (AMMs). (a) FWHM vs. peak position of $\mathrm{G}$ band, (b) FWHM vs. peak position of $\mathrm{D}$ band, (c) the peak intensity ratio $\left(I_{\mathrm{D}} / I_{\mathrm{G}}\right)$ vs. band area ratio $\left(A_{\mathrm{D}} / A_{(\mathrm{D}+\mathrm{G})}\right)$.

Table 2. Summarized Raman parameters such as peak position, FWHM, the peak intensity ratio $\left(I_{\mathrm{D}} / I_{\mathrm{G}}\right)$, band area ratio $\left(A_{\mathrm{D}} / A_{(\mathrm{D}+\mathrm{G})}\right)$ for $\mathrm{G}$ and $\mathrm{D}$ bands of the Antarctic micrometeorites (AMMs).

\begin{tabular}{|c|c|c|c|c|c|c|}
\hline \multirow{2}{*}{ Sample name } & \multicolumn{2}{|c|}{$\mathrm{G}$ band } & \multicolumn{2}{|c|}{ D band } & \multirow{2}{*}{$I_{\mathrm{D}} / I_{\mathrm{G}}$} & \multirow{2}{*}{$A_{\mathrm{D}} / A_{(\mathrm{D}+\mathrm{G})}(\%)$} \\
\hline & Peak position $\left(\mathrm{cm}^{-1}\right)$ & FWHM $\left(\mathrm{cm}^{-1}\right)$ & Peak position $\left(\mathrm{cm}^{-1}\right)$ & FWHM $\left(\mathrm{cm}^{-1}\right)$ & & \\
\hline \multicolumn{7}{|l|}{ AMM } \\
\hline Y98K11KS004 & $1586 \sim 1593$ & $81 \sim 106$ & $1358 \sim 1371$ & $200 \sim 225$ & $1.14 \sim 1.33$ & $67.8 \sim 75.9$ \\
\hline Y98K11KS010 & $1582 \sim 1592$ & $92 \sim 105$ & $1360 \sim 1373$ & $211 \sim 256$ & $1.15 \sim 1.40$ & $71.4 \sim 74.9$ \\
\hline Y98K11KS020-1 & $1582 \sim 1589$ & $95 \sim 111$ & $1360 \sim 1367$ & $166 \sim 224$ & $1.16 \sim 1.29$ & $64.7 \sim 71.2$ \\
\hline Y98K11KS020-2 & $1590 \sim 1595$ & $87 \sim 99$ & $1359 \sim 1365$ & $204 \sim 231$ & $1.16 \sim 1.23$ & $70.2 \sim 71.7$ \\
\hline Y98K11KS023-1 & $1589 \sim 1593$ & $95 \sim 109$ & $1359 \sim 1366$ & $221 \sim 244$ & $1.17 \sim 1.23$ & $70.6 \sim 72.6$ \\
\hline Y98K11KS023-2 & $1588 \sim 1590$ & $99 \sim 106$ & $1362 \sim 1366$ & $242 \sim 265$ & $1.13 \sim 1.30$ & $70.8 \sim 73.5$ \\
\hline Y98K11KS026 & $1588 \sim 1593$ & $87 \sim 107$ & $1361 \sim 1368$ & $222 \sim 261$ & $1.10 \sim 1.37$ & $69.9 \sim 78.3$ \\
\hline Y98K11KS037 & $1583 \sim 1591$ & $92 \sim 109$ & $1362 \sim 1373$ & $222 \sim 265$ & $1.10 \sim 1.31$ & $71.1 \sim 74.4$ \\
\hline Y98K11KS077-1 & $1583 \sim 1589$ & $97 \sim 133$ & $1358 \sim 1373$ & $195 \sim 261$ & $1.19 \sim 1.61$ & $69.1 \sim 74.7$ \\
\hline Y98K11KS093-1 & $1586 \sim 1593$ & $94 \sim 110$ & $1363 \sim 1371$ & $218 \sim 235$ & $1.16 \sim 1.32$ & $69.4 \sim 73.7$ \\
\hline Y98K11KS093-2 & $1585 \sim 1589$ & $99 \sim 119$ & $1357 \sim 1367$ & $199 \sim 236$ & $1.14 \sim 1.22$ & $66.2 \sim 71.8$ \\
\hline \multicolumn{7}{|c|}{ Carbonaceous chondrites } \\
\hline CI1s*a & $1588 \sim 1600$ & $97 \sim 157$ & $1361 \sim 1394$ & $218 \sim 384$ & $0.76 \sim 1.34$ & $54.6 \sim 80.0$ \\
\hline Tagish Lake*b & $1591 \sim 1597$ & $74 \sim 115$ & $1371 \sim 1402$ & $305 \sim 380$ & $0.78 \sim 1.02$ & $68.3 \sim 76.3$ \\
\hline $\mathrm{CM} 2 \mathrm{~s}^{* \mathrm{c}}$ & $1588 \sim 1595$ & $90 \sim 138$ & $1356 \sim 1376$ & $231 \sim 365$ & $0.70 \sim 1.16$ & $55.4 \sim 73.2$ \\
\hline $\mathrm{CR} 2 * \mathrm{~d}$ & $1587 \sim 1599$ & $77 \sim 121$ & $1355 \sim 1376$ & $202 \sim 335$ & $0.78 \sim 0.94$ & $58.6 \sim 74.4$ \\
\hline $\mathrm{CV} 3 \mathrm{~s}^{* \mathrm{e}}$ & $1592 \sim 1606$ & $60 \sim 128$ & $1346 \sim 1357$ & $50 \sim 127$ & $1.20 \sim 1.83$ & $47.8 \sim 61.2$ \\
\hline CO3 (Moss) & $1596 \sim 1603$ & $46 \sim 66$ & $1343 \sim 1351$ & $63 \sim 69$ & $1.13 \sim 1.22$ & $53.6 \sim 62.5$ \\
\hline
\end{tabular}

*a: Data from CI1 carbonaceous chondrites (Ivuna, Orgueil, Alais) after Raynal (2003).

*b: Data from Tagish Lake carbonaceous chondrites after Matrajt et al. (2004).

*c: Data from CM2 carbonaceous chondrites (Murchison, Murray, Cold Bokkeveld) after Raynal (2003).

*d: Data from CR2 carbonaceous chondrites (Renazzo) after Raynal (2003).

*e: Data from CV3 carbonaceous chondrites (Allende, Axtell) after Raynal (2003).

we did not find this 500-nm band in the visible spectra for carbonaceous chondrites (Ivuna C1, Murchison C2 and Allende C3). The presence of this 500-nm band can also be taken as an indicator of Antarctic weathering (Table 3).

\subsection{IR spectroscopy}

IR spectra of all the analyzed AMMs show a very broad band at $3,400 \mathrm{~cm}^{-1}$ together with a smaller band around $1630 \mathrm{~cm}^{-1}$ (Fig. 5(a)). These bands are consid- 


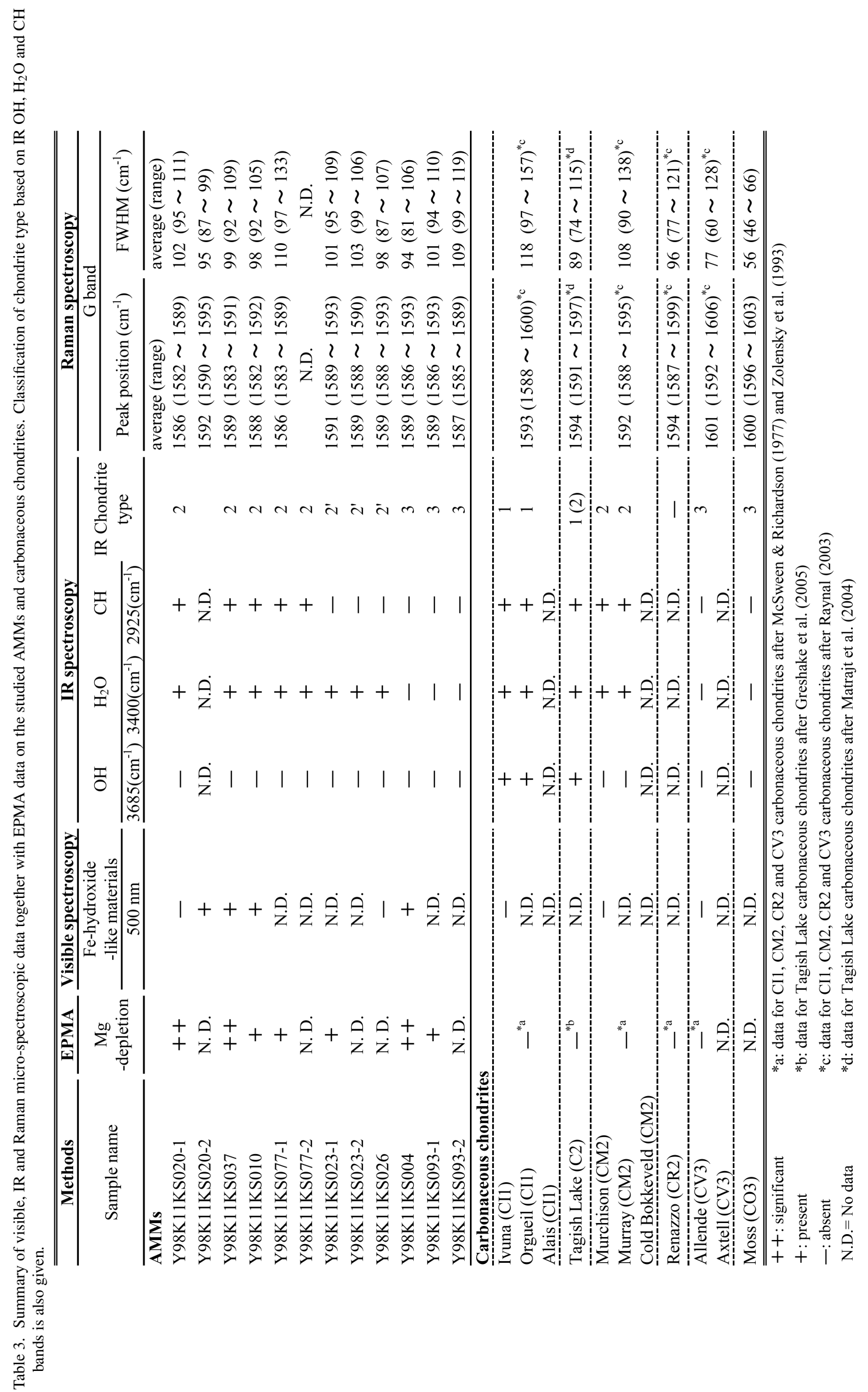



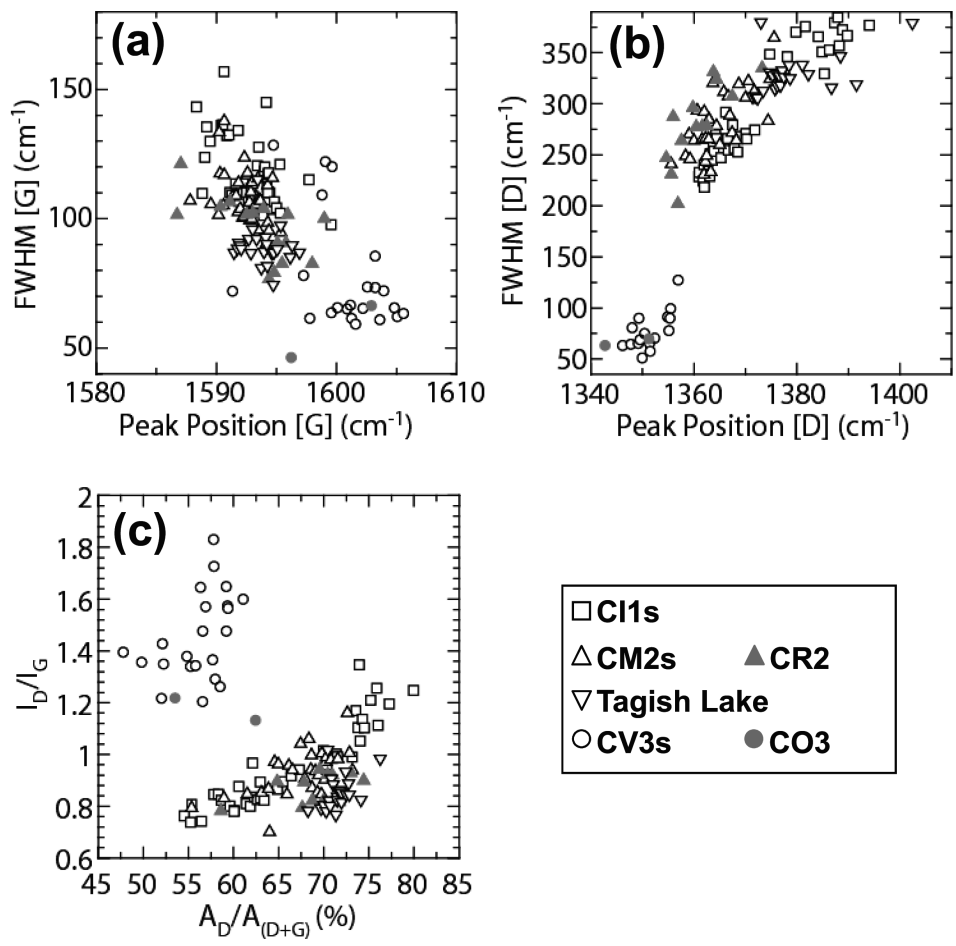

Fig. 8. The correlation diagrams of Raman parameters for G and D bands of carbonaceous chodrites. Except for CO3 measured in this study, CI1s, CM2s, CR2 and CV3s data are from Raynal (2003) and Tagish Lake data from Matrajt et al. (2004). (a) FWHM vs. peak position of G band, (b) FWHM vs. peak position of D band, (c) the peak intensity ratio $\left(I_{\mathrm{D}} / I_{\mathrm{G}}\right)$ vs. band area ratio $\left(A_{\mathrm{D}} / A_{(\mathrm{D}+\mathrm{G})}\right)$.

ered to be due to hydrogen-bonded liquid-like molecular water (Nakamoto et al., 1955; Aines and Rossman, 1984), which may derive from the absorbed water in phyllosilicates. Nakamura et al. (2001), Noguchi et al. (2002), and Nakamura and Noguchi (2004) reported that the vast majority of phyllosilicate-rich AMMs contain saponite as the major phyllosilicate. This kind of phyllosilicate is generally known to be formed during aqueous alteration of carbonaceous chondrites (Jones and Brearley, 2006). However, Noguchi et al. (1999) also showed the possibility of minute phyllosilicates being generated by Antarctic weathering. The presence of the $3,400 \mathrm{~cm}^{-1}$ band can therefore be an indicator of aqueous alteration with some possible contribution of Antarctic weathering (Table 3).

The IR spectra of some of the AMMs (Fig. 5(a)) display two peaks around 2,925 and $2,960 \mathrm{~cm}^{-1}$, due to asymmetric $\mathrm{CH}_{2}$ and $\mathrm{CH}_{3}$ stretching vibrations, respectively. These two peaks indicate the presence of aliphatic hydrocarbons in some of the AMMs (Table 3).

\subsection{Raman spectroscopy}

Raman spectra of all the AMMs show two Raman bands, namely the D and G bands (Ferrari and Robertson, 2000) (Table 2). Both bands are broad, indicating the less ordered natures of the carbonaceous materials. Furthermore, significant fluorescence emission backgrounds in the Raman spectra (Fig. 6(b)) provide evidence for the presence of amorphous graphitic structures (Raynal, 2003).

The mean diameter of graphene-like sheets $\left(L_{\mathrm{a}}\right)$ (Pasteris and Wopenka, 1991) of the AMMs has been estimated to be $20 \sim 30 \AA$ based on the $L_{\mathrm{a}}$ vs. $A_{\mathrm{D}} / A_{(\mathrm{D}+\mathrm{G})}$ relation (Wopenka and Pasteris, 1993). This $L_{\mathrm{a}}$ value is similar to that reported for Tagish Lake organics (about $20 \AA \AA$ ) (Nakamura et al.,
2002). The graphene-like structures for the studied AMMs are possibly similar to those for aqueously altered carbonaceous chondrites.

\subsection{Spectroscopic classification of carbonaceous chon- drites}

4.4.1 IR spectroscopy The classification of carbonaceous chondrites by IR spectroscopy has been reported by Osawa et al. (2005) using the peak height ratios of hydrous components. We suggest here an alternative classification based on the criteria of carbonaceous chondrites in terms of the existence or absence of peaks of $3,685,3,400$, and $2,925 \mathrm{~cm}^{-1}$ (Table 3).

Hydrous phyllosilicates, such as serpentine-group minerals, have generally a sharp peak around $3,685 \mathrm{~cm}^{-1}$ due to $\mathrm{OH}$ species bound to the mineral lattice (Osawa et al., 2005). This phyllosilicate peak was observed for the CI1 and Tagish Lake carbonaceous chondrites, but not for the CM2 and CR2 carbonaceous ones (Fig. 5(b)). However, CM2 carbonaceous chondrites, such as Murchison, have been reported to contain phyllosilicates (Osawa et al., 2001). The IR spectroscopy appears to be unable to detect trace phyllosilicates. The presence of the $3,685 \mathrm{~cm}^{-1}$ peak can indicate the presence of chondrite type 1 plus Tagish Lake type (Table 3).

A very broad band at $3,400 \mathrm{~cm}^{-1}$ was observed for CI1, CM2, CR2, and Tagish Lake carbonaceous chondrites but not for the CO3 and CV3 ones (Fig. 5(b)). The presence of this $3,400 \mathrm{~cm}^{-1}$ band can indicate the presence of chondrite types 1 or 2 (Table 3 ).

Aliphatic C-H bands were detected at $2,925 \mathrm{~cm}^{-1}$ together with the smaller $2,960 \mathrm{~cm}^{-1}$ band in CI1, CM2, CR2 and Tagish Lake carbonaceous chondrites but not in 

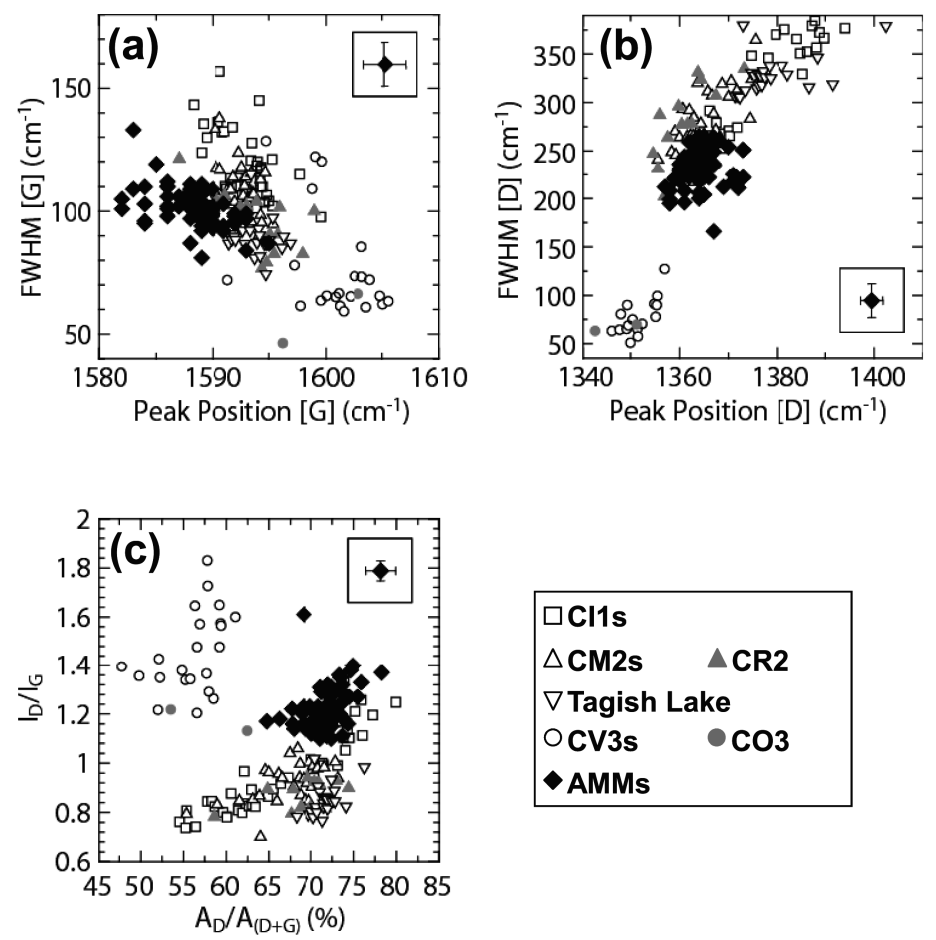

Fig. 9. The correlation diagrams of Raman parameters for $\mathrm{G}$ and $\mathrm{D}$ bands of the Antarctic micrometeorites (AMMs) and carbonaceous chodrites. (a) FWHM vs. peak position of G band, (b) FWHM vs. peak position of D band, (c) the peak intensity ratio $\left(I_{\mathrm{D}} / I_{\mathrm{G}}\right)$ vs. band area ratio $\left(A_{\mathrm{D}} / A_{(\mathrm{D}+\mathrm{G})}\right)$.

the CO3 and CV3 ones (Fig. 5(b)). The presence of the $2,925 \mathrm{~cm}^{-1}$ band can correspond to chondrite types 1 or 2 (Table 3).

Therefore, the presence of the 3,685, 3,400, and $2,925 \mathrm{~cm}^{-1}$ bands can correspond to type 1 chondrite, the presence of the 3,400 and 2,925 bands without the $3,685 \mathrm{~cm}^{-1}$ band can correspond to type 2 , and the absence of these bands can correspond to type 3. Although Tagish Lake is mineralogically grouped into type 2 , it corresponds to type 1 based on the present criteria (Table 3).

4.4.2 Raman spectroscopy The Raman parameters for primitive carbonaceous chondrites (Orgueil, Alais, Ivuna CI1; Murchison, Cold Bokkeveld, Murray CM2; Renazzo CR2; Tagish Lake C2, Allende and Axtell CV3) in the literature (Raynal, 2003; Matrajt et al., 2004) and Moss CO3 (this study) were also plotted in our figures (Fig. 8(ac)) and summarized in Table 2 .

The peak position of the $G$ band for the carbonaceous chondrites tends to become smaller-from about $1,605 \mathrm{~cm}^{-1}$ for type 3 to about $1,585 \mathrm{~cm}^{-1}$ for type 1 (Fig. 8(a)) - indicating a more amorphous nature. The FWHM of the $\mathrm{G}$ band for the carbonaceous chondrites tends to become larger-from about $60 \mathrm{~cm}^{-1}$ for type 3 to about $160 \mathrm{~cm}^{-1}$ for type 1 (Fig. 8(a)) — indicating a more amorphous nature (Ferrari and Robertson, 2000).

The peak position of the D band for the carbonaceous chondrites tends to become larger-from about $1,350 \mathrm{~cm}^{-1}$ for type 3 to about $1,390 \mathrm{~cm}^{-1}$ for type 1 (Fig. 8(b)). The FWHM of the D band for the carbonaceous chondrites tends to become larger-from about $70 \mathrm{~cm}^{-1}$ for type 3 to about $380 \mathrm{~cm}^{-1}$ for type 1 (Fig. 8(b)) —indicating a more amorphous nature (Wopenka and Pasteris, 1993).

The band intensity ratio $I_{\mathrm{D}} / I_{\mathrm{G}}$ for the type 3 carbona- ceous chondrites is larger (1.8-1.2) than others reported. The one for type 2 has smaller values of between 1.1 and 0.7 . This $I_{\mathrm{D}} / I_{\mathrm{G}}$ ratio for type 1 shows similar ranges: $1.3-$ 0.7 (Fig. 8(c)).

The band area ratio $A_{\mathrm{D}} / A_{(\mathrm{D}+\mathrm{G})}(\%)$ for the type 3 carbonaceous chondrites is smaller (45-60\%) than the others. The one for type 2 has larger values of between 55 and $75 \%$. This $A_{\mathrm{D}} / A_{(\mathrm{D}+\mathrm{G})}(\%)$ ratio for type 1 shows similar ranges of between 55 and $80 \%$ (Fig. 8(c)).

\subsection{Spectroscopic classification of AMMs}

4.5.1 IR spectroscopy The classification for carbonaceous chondrites based on the presence of the 3,685 , 3,400 , and $2,925 \mathrm{~cm}^{-1}$ bands can be applied to the AMMs studied here. The presence of the 3,685, 3,400, and $2,925 \mathrm{~cm}^{-1}$ bands can correspond to type 1 chondrite, the presence of the 3,400 and $2,925 \mathrm{~cm}^{-1}$ bands without the $3,685 \mathrm{~cm}^{-1}$ band can correspond to type 2 , and the absence of these bands can correspond to type 3 (Table 3 ).

Based on this classification criterion, Y98K11KS010, Y98K11KS020-1, Y98K11KS037, and Y98K11KS0771,2 are classified as type 2. Y98K11KS023-1, 2 and Y98K11KS026 can be classified to type 2 by the presence of the $\mathrm{H}_{2} \mathrm{O}$ band. However, they do not show the $2,925 \mathrm{~cm}^{-1}$ band, and they can be designated as type $2^{\prime}$. Y98K11KS004 and Y98K11KS093-1, 2 are classified as type 3 (Table 3 ).

4.5.2 Raman spectroscopy The peak position and the FWHM of the G band ranges of AMMs were found to mainly overlap those for CM2 carbonaceous chondrites (Fig. 9(a)) and those of the D band region for the AMMs to mainly overlap with the region for CI1s (Fig. 9(b)). The $\mathrm{D}$ peak position range of the AMMs can be seen to be similar to those for CM2 and CR2 chondrites (Fig. 9(b)). 
The $I_{\mathrm{D}} / I_{\mathrm{G}}$ and $A_{\mathrm{D}} / A_{(\mathrm{D}+\mathrm{G})}(\%)$ distributions of the AMMs are close to those of the CI1 carbonaceous chondrites, and the $A_{\mathrm{D}} / A_{(\mathrm{D}+\mathrm{G})}$ band area ratios $(\%)$ of the AMMs are in a similar range to those for CR2 and Tagish Lake carbonaceous chondrites (Fig. 9(c)). The results of Raman analysis suggest that, although some data deviates slightly, the aromatic carbonaceous material in the studied AMMs is different from type 3 carbonaceous chondrites and rather similar to types 1 and 2 carbonaceous chondrites. In fact, the PAHs in AMMs were reported to have some similarity to those in CM2 carbonaceous chondrites (Clemett et al., 1998).

\subsection{The relation of AMMs with carbonaceous chon- drites}

The weathering effects on the studied AMMs can be indicated by the $\mathrm{Mg}$ depletion, as evidenced from the EPMA analyses, and the presence of a 500-nm band due to Fe-hydroxide-like materials, based on visible microspectroscopy results (Table 3). The IR and Raman data for AMMs and carbonaceous chondrites are also summarized in Table 3.

All of the AMMs appear to show varying degrees of weathering. The weathering effects on organic materials during residence in Antarctic ice (Tyra et al., 2007) are not yet well understood. Sephton et al. (2004) suggested that Antarctic weathering may have similar effects as the parent body aqueous alteration by removing ether bonds from organic material and alkyl side chains from its constituent units (Sephton et al., 2004).

The IR $\mathrm{H}_{2} \mathrm{O}$ and $\mathrm{CH}$ bands of the AMMs showed no clear relation to these weathering effects (Table 3). It should be noted that, despite the $\mathrm{Mg}$ depletion and the presence of Fe-hydroxide-like materials, Y98K11KS004 is similar to type 3 carbonaceous chondites without the presence of the hydrous phases (Table 3). The Raman parameters of the AMMs are in a relatively similar range regardless of the weathering degree. However, G band peak positions for some AMM grains deviate from the clustered region to the smaller values (left hand side in Fig. 7(a)). This slight disordering of graphic materials for some AMMs may possibly be due to Antarctic weathering.

Other effects, such as heating effects during atmospheric entry on the AMMs, should also be considered. Matrajt et al. (2006) reported that organics in unmelted micrometeorites can be lost either by thermal degradation or evaporation upon atmospheric entry. They also pointed out the possible survival of some organic molecules in micrometeorites after atmospheric entry. The G band FWHM values for one AMM grain (Y98K11KS004) deviated somewhat from the clustered region to smaller values (downward in Fig. 7(a)). This slight ordering may be due to heating during atmospheric entry. However, the heating effects may be variable and could not be evaluated in the study reported here.

Although Y98K11KS004 have clear weathering evidences, it does not show hydrous IR features. Hydrous phyllosilicate formation during Antarctic weathering might not be significant compared with $\mathrm{Mg}$-depletion and ironhydroxide-like material formation. Raman parameters for this AMM particle are similar to type 2 or 1 carbonaceous chondrites despite the heating during atmospheric entry.
Therefore, we conclude that the IR and Raman features of the AMMs may retain at least some original characters before Antarctic weathering. Our multi-method approach can be useful for the genetic classification of AMMs in terms of any discussion on its parent body. Tomeoka et al. (2003) suggested that hydrous asteroids will produce much more abundant fragments than anhydrous asteroids during the asteroidal collision. This may be due to the wet and porous natures of these hydrous asteroids. Abundant dust particles are formed before arriving on the earth's surface as carbonaceous chondrites and micrometeorites (Tomeoka et al., 2003). Reflectance spectroscopy measurements (Jones et al., 1990) indicate that 30-40\% of known asteroids are hydrated CI-CM-like asteroids, which are possible parent bodies of CI-CM chondrites (Tomeoka et al., 2003). Since the micrometeorites are defined only by size-i.e., smaller than $1 \mathrm{~mm}$, AMMs may also have an origin in similar parent bodies as carbonaceous chondrites.

For the further understanding of original organic and hydrous components in AMMs without the weathering effects, fresh AMMs should be measured by the present multimethods.

\section{Conclusions}

We investigated eight unmelted Antarctic micrometeorite grains (AMMs) by pressing these on Al-foils and measuring by IR, Raman, and visible reflection micro-spectroscopy in combination with EPMA analyses. These data were compared with those for carbonaceous chondrites. The following results were obtained.

1) The elemental compositions of AMMs show $\mathrm{Mg}$ depletion (Table 3), suggesting their weathering in Antarctic ice sheets.

2) The visible reflectance spectra of some of the AMMs show a weak absorption band around $500 \mathrm{~nm}$ due to the presence of Fe-hydroxide-like materials. On the other hand, this band cannot be recognized in visible reflectance spectra of carbonaceous chondrites (Table 3). This difference may also indicate the Antarctic weathering.

3) The $\mathrm{OH}, \mathrm{H}_{2} \mathrm{O}$, and $\mathrm{CH}$ bands in the transmissionreflection IR spectra can be used to classify the AMMs into carbonaceous chondrite types (Table 3). Using these criteria, four AMM grains were classified into type 2, while two grains were classified into type 3 .

4) The Raman features of $D$ (disordered: $1360 \mathrm{~cm}^{-1}$ ) and $\mathrm{G}$ (graphite: $1600 \mathrm{~cm}^{-1}$ ) bands of graphitic carbonaceous materials in the AMMs are not similar to those for type 3 but rather close to those for type 2 and 1 carbonaceous chondrites, although some data shows a certain degree of deviation.

5) The weathering effects in Antarctic ice sheets and heating effects during atmospheric entry on AMMs should be evaluated for the presence of organic and hydrous components.

6) The genetic classification of individual AMM grains can be conducted using the multiple microspectroscopic reflectance methods on the same sample configuration pressed on Al-foils. These methods will 
also be useful for characterizating any precious small samples.

Acknowledgments. We thank the members of the National Institute for Polar Research for giving us the micrometeorite samples. We are grateful to Janet Borg and Pierre-Ivan Raynal for providing Raman data on carbonaceous chondrites. We also thank Y. Kebukawa and M. Zolensky for providing me many kinds of carbonaceous chondrites. Detailed comments by an anonymous reviewer and Dr. T. Osawa greatly improved the manuscript. This work was financially supported by the research fellowship of Osaka University to A. S.

\section{References}

Aines, R. D. and G. R. Rossman, Water in minerals? A peak in the infrared, J. Geophys. Res., 89, 4059-4071, 1984.

Amri, C. El, M. C. Maurel, G. Sagon, and M. H. Baron, The microdistribution of carbonaceous matter in the Murchison meteorite as investigated by Raman imaging, Spectrochim. Acta A, 61, 2049-2056, 2005.

Anders, E. and N. Grevesse, Abundances of the elements-Meteoritic and solar, Geochim. Cosmochim. Acta, 53, 197-214, 1989.

Badjukov, D. D. and J. Raitala, Micrometeorites from the northern ice cap of the Novaya Zemlya archipelago, Russia: The first occurence, Meteorite Planet. Sci., 38, 329-340, 2003.

Bland, P. A., Quantification of meteorite infall rates from accumulations in deserts, and meteorite accumulations on Mars, in Accretion of extraterrestrial matter throughout Earth's history, edited by PeuckerEhrenbrink, B. and B. Schmitz, 466 pp., Plenum Publishers, 2001.

Bonal, L., E. Quirico, M. Bourot-Denise, and G. Montagnac, Determination of the petrologic type of CV3 chondrites by Raman spectroscopy of included organic matter, Geochim. Cosmochim. Acta, 70, 1849-1863, 2006.

Brinton, K. L. F., C. Engrand, D. P. Glavin, J. L. Bada, and M. Maurette, A search for extraterrestrial amino acids in carbonaceous Antarctic micrometeorites, Origin Life Evol. Biosphere, 28, 413-424, 1998.

Brownlee, D. E., B. Bates, and L. Schramm, The elemental composition of stony cosmic spherules, Meteorite Planet. Sci., 32, 157-175, 1997.

Busemann, H., C. M. O. D. Alexander, and L. R. Nittler, Characterization of insoluble organic matter in primitive meteorites by microRaman spectroscopy, Meteorite Planet. Sci., 42, 1387-1416, 2007.

Clemett, S. J., X. D. F. Chillier, S. Gillette, R. N. Zare, M. Maurette, C. Engrand, and G. Kurat, Observation of indigenous polycyclic aromatic hydrocarbons in "Giant" carbonaceous Antarctic micrometeorites, Origin Life Evol. Biosphere, 28, 425-448, 1998.

Cronin, J. R., S. Pizzarello, and D. Cruikshank, Organic matter in carbonaceous chondrites, planetary satellites, asteroids and comets, in $\mathrm{Me}$ teorites and the Early Solar System, edited by M. S. Matthews and J. F. Kerridge, 819 pp., Univ. of Arizona Press, 1988.

Dai, Z. R., J. P. Bradley, D. J. Joswiak, D. E. Brownlee, and M. J. Genge, Nano-diamonds in Interplanetary Dust Particles (IDPs), micrometeorites, and meteorites, Lunar Planet. Sci., 33, \#1321, 2002.

D'Hendecourt, L. B. and L. J. Allamandola, Time dependent chemistry in dense molecular clouds. III-Infrared band cross sections of molecules in the solid state at $10 \mathrm{~K}$, Astron. Astrophys., 64, 453-467, 1986.

Ehrenfreund, P., W. Irvine, L. Becker, J. Blank, J. R. Brucato, L. Colangeli, S. Derenne, D. Despois, A. Dutrev, H. Fraaije, A. Lazcano, T. Owen, and F. Robert, Astrophysical and astrochemical insights into the origin of life, Rep. Prog. Phys., 65, 1427-1487, 2002.

Engrand, C. and M. Maurette, Carbonaceous micrometeorites from Antarctica, Meteorite Planet. Sci., 33, 565-580, 1998.

Engrand, C., E. DeLoule, F. Robert, M. Maurette, and G. Kurat, Extraterrestrial water in micrometeorites and cosmic spherules from Antarctica: An ion microprobe study, Meteorite Planet. Sci., 34, 773-786, 1999.

Ferrari, A. C. and J. Robertson, Interpretation of Raman spectra of disordered and amorphous carbon, Phys. Rev. B, 61, 14095-14107, 2000.

Flynn, G. L., L. P. Keller, C. Jacobsen, and S. Wirick, FTIR and carbonXANES examination of organic carbon in Tagish Lake: Evidence for a moderately volatile organic component, Lunar Planet. Sci., \#1593, 2001.

Genge, M. J., M. M. Grady, and R. Hutchison, The texture and compositions of fine-grained Antarctic micrometeorites: Implications for comparisons with meteorites, Geochim. Cosmochim. Acta, 61, 5149-5162, 1997.
Gounelle, M., C. Engrand, M. Maurette, G. Kurat, K. D. McKeegan, and F. Brandstätter, Small Antarctic micrometeorites; A mineralogical and in situ oxygen isotope study, Meteorite Planet. Sci., 40, 917-932, 2005.

Grady, M. M., Catalogue of Meteorites, 689 pp., Cambridge University Press, Cambridge, U.K., 2000.

Graves, P. R., C. Johnston, and J. J. Campaniello, Raman scattering in spinel structure ferrites, Mat. Res. Bull., 23, 1651-1660, 1988.

Greshake, A., A. N. Krot, G. J. Flynn, and K. Keil, Fine-grained dust rimes in the Tagish Lake carbonaceous chondrite: Evidence for parent body alteration, Meteorite Planet. Sci., 40, 1413-1431, 2005.

Grun, E., H. A. Zokk, H. Fechtig, and R. H. Giese, Collisional balance of the meteoritic complex, Icarus, 62, 244-272, 1985.

Hughes, D. W., Meteors, in Cosmic dust, edited by J. A. M. McDonnell, 714 pp., John Wiley and Sons Ltd., 1978.

Jones, C. L. and A. J. Brearley, Experimental aqueous alteration of the Allende meteorite under oxidizing conditions: Constrains on asteroidal alteration, Geochim. Cosmochim. Acta, 70, 1040-1058, 2006.

Jones, T. D., L. A. Lebofsky, J. S. Lewis, and M. S. Marley, The composition and origin of the $\mathrm{C}, \mathrm{P}$, and $\mathrm{D}$ asteroids: water as a tracer of thermal evolution in the outer belt, Icarus, 88, 172-192, 1990.

Kurat, G., T. Presper, and F. Brandstätter, CI-like micrometeorites from CAP Prudhomme, Antarctica, Lunar Planet. Sci., \#747, 1992a.

Kurat, G., C. Koeberl, T. Presper, F. Brandstätter, and M. Maurette, Bulk compositions of Antarctic micrometerorites: Nebular and terrestrial signature, Meteoritics, 27, 246, 1992 b.

Kurat, G., C. Koeberl, T. Presper, F. Brandstätter, and M. Maurette, Petrology and geochemistry of Antarctic micrometeorites, Geochim. Cosmochim. Acta, 58, 3879-3904, 1994.

Love, S. G. and D. E. Brownlee, A direct measurement of the terrestrial mass accretion rate of cosmic dust, Science, 262, 550-553, 1993.

Matrajt, G., M. Maurette, and D. Blanot, Ferrihydrite in micrometeorites: A potential adsorbent of amino acids and catalyst of oligopeptide formation, Lunar Planet. Sci., \#1037, 2001.

Matrajt, G., J. Borg, P. I. Raynal, Z. Djouadi, L. d'Hendecourt, G. Flynn, and D. Deboffle, FTIR and Raman analyses of the Tagish Lake meteorite: Relationship with the aliphatic hydrocarbons observed in the Diffuse Interstellar Medium, Astron. Astrophys., 416, 983-990, 2004.

Matrajt, G., D. Brownlee, M. Sadilek, and L. Kruse, Survival of organic phases in porous IDPs during atmospheric entry: A pulse-heating study, Meteorite Planet. Sci., 41, 903-911, 2006.

Maurette, M., Micrometeorites and the Mysteries of Our Origins, 330 pp., Springer, 2006.

McSween, H. Y. and S. M. Richardson, The composition of carbonaceous chodnrite matrix, Geochim. Cosmochim. Acta, 41, 1145-1161, 1977.

Nagano, T., H. Isobe, S. Nakashima, and M. Ashizaki, Characterization of iron hydroxides in a weathered rock surface by visible microspcetrosocopy, Appl. Spectrosc., 56, 651-657, 2002.

Nakamoto, K., M. Margoshes, and R. E. Rundle, Stretching frequencies as a function of distances in hydrogen bonds, J. Am. Chem. Soc., 77, 6480-6486, 1955.

Nakamura, K., M. E. Zolensky, S. Tomita, S. Nakashima, and K. Tomeoka, Hollow organic globules in the Tagish Lake meteorite as possible products of primitive organic reactions, Int. J. Astrobiol., 1, 179-189, 2002.

Nakamura, T. and T. Noguchi, Characteristics of phyllosilicates in micrometeorites derived from synchrotron X-ray diffraction analysis, $\mathrm{Lu}$ nar Planet. Sci., \#5074, 2004.

Nakamura, T., T. Noguchi, T. Yada, Y. Nakamuta, and N. Takaoka, Bulk mineralogy of individual micrometeorites determined by $\mathrm{X}$-ray diffraction analysis and transmission electron microscopy, Geochim. Cosmochim. Acta, 65, 4385-4397, 2001.

Noguchi, T. and T. Nakamura, Mineralogy of Antarctic micrometeorites recovered from the Dome Fuji Station, Antarct. Meteorite Res., 13, 285301, 2000.

Noguchi, T., K. Ishikawa, and K. Ninagawa, Effects of terrestrial weathering on the matrix mineralogy of colony $\mathrm{CO} 3$ chondrite, Antarct. Meteorite Res., 12, 36-56, 1999.

Noguchi, T., T. Nakamura, and W. Nozaki, Mineralogy of phyllosilicaterich micrometeorites and comparison with Tagish Lake and Sayama meteorites, Earth Planet. Sci. Lett., 202, 229-246, 2002.

Okumura, S. and S. Nakashima, Water diffusivity in rhyolitic glasses as determined by in situ IR spectroscopy, Phys. Chem. Miner., 31, 183189, 2004.

Osawa, T., H. Kagi, and K. Nagao, Mid-infrared transmission spectra of individual Antarctic micrometeorites and carbonaceous chondrites, Antarct. Meteorite Res., 14, 71-88, 2001.

Osawa, T., T. Nakamura, and K. Nagao, Noble gas isotopes and mineral assemblages of Antarctic micrometeorites collected at the meteorite ice 
field around the Yamato Mountains, Meteorite Planet. Sci., 38, 16271640, 2003.

Osawa, T., H. Kagi, T. Nakamura, and T. Noguchi, Infrared spectroscopic taxonomy for carbonaceous chondrites from speciation of hydrous components, Meteorite Planet. Sci., 40, 71-86, 2005.

Pasek, M. and D. Lauretta, Extraterrestrial flux of potentially prebiotic C, $\mathrm{N}$, and $\mathrm{P}$ to the early earth, Origin Life Evol. Biosphere, 38, 5-21, 2008.

Pasteris, J. D. and B. Wopenka, Raman spectra of graphite as indicators of degree of metamorphism, Can. Mineral., 29, 1-9, 1991.

Peucker-Ehrenbrink, B. and G. Ravizza, The effects of sampling artifacts on cosmic dust flux estimates: A reevaluation of nonvolatile tracers (Os, Ir), Geochim. Cosmochim. Acta, 64, 1965-1970, 2000.

Presper, T., G. Kurat, C. Koeberl, H. Palme, and M. Maurette, Elemental depletions in Antarctic micrometeorites and Arctic cosmic spherules: Comparison and relationships, Lunar Planet. Sci., \#1177, 1993.

Raynal, P. I., Méthodes instrumentales en astrophysique et leurs applications spatiales, Ph.D. Thesis, Université Pierre et Marie Curie, Paris, France, 2003.

Scheinost, A. C., A. Chavernas, V. Barrón, and J. Torrent, Use and limitations of second-derivative diffuse reflectance spectroscopy in the visible to near-infrared range to identify and quantify Fe oxide minerals in soils, Clays Clay Miner., 46, 528-536, 1998.

Sephton, M. A., P. A. Bland, C. T. Pillinger, and I. Gilmou, The preservation state of organic matter in meteorites from Antarctica, Meteorite Planet. Sci., 39, 747-754, 2004.

Sherman, D. M. and T. D. Waite, Electronic spectra of $\mathrm{Ge}^{3+}$ oxides and oxide hydroxides in the niar IR to near UV, Am. Miner., 70, 1262-1269, 1985.

Stevenson, F. J., Humus chemistry: genesis, composition, reactions, 496 pp., John Wiley and Sons, 1994.

Terada, K., T. Yada, H. Kojima, T. Noguchi, T. Nakamura, T. Murakami, H. Yano, W. Nozaki, Y. Nakamuta, N. Matsumoto, J. Kamata, T. Mori, I. Nakai, M. Sasaki, M. Itabashi, T. Setoyanagi, K. Nagao, T. Osawa, H. Hiyagon, S. Mizutani, T. Fukuoka, K. Nogami, R. Ohmori, and H. Ohashi, General characterization of Antarctic micrometeorites collected by the 39th Japanese Antarctic Reserch Expedition: Consortium studies of JARE AMMs (III), Antarct. Meteorite Res., 14, 89-107, 2001.
Tomeoka, K., K. Kiriyama, K. Nakamura, Y. Yamahana, and T. Sekine, Interplanetary dust from the explosive dispersal of hydrated asteroids by impacts, Nature, 423, 60-62, 2003.

Tyra, M. A., J. Farquhar, B. A. Wing, G. K. Benedix, A. J. T. Jull, T. Jackson, and M. H. Thiemens, Terrestrial alteration of carbonate in a suite of Antarcic CM chondrites: Evidence from oxygen and carbon isotopes, Geochim. Cosmochim. Acta, 71, 782-795, 2007.

Wopenka, B., Raman observations on individual interplanetary dust particles, Earth Planet. Sci. Lett., 88, 221-231, 1988.

Wopenka, B. and J. D. Pasteris, Structural characterization of kerogens to granulite-facies graphite: applicability of Raman microprobe spectroscopy, Am. Miner., 78, 533-557, 1993.

Wright, P. I., P. Yates, R. Hutchison, and C. T. Pillinger, The content and stable isotopic composition of carbon in individual micrometeorites from Greenland and Antarctica, Meteorite Planet. Sci., 32, 79-89, 1997.

Yada, T. and H. Kojima, The collection of micrometeorites in the Yamato Meteorite Ice Field of Antarctica in 1998, Antarct. Meteorite Res., 13, 9-18, 2000.

Yada, T., T. Nakamura, N. Takaoka, T. Noguchi, K. Terada, H. Yano, T. Nakazawa, and H. Kojima, The global accretion rate of extraterrestrial materials in the last glacial period estimated from the abundance of micrometeorites in Antarctic glacier ice, Earth Planets Space, 56, 6779, 2004.

Yamanoi, Y., S. Nakashima, S. Okumura, and S. Takeuchi, Color change measurements of a scoria and simulation heating experiments by spectro-colorimetry, Bull. Volcanol. Soc. Jpn., 49, 317-331, 2004.

Yamanoi, Y., S. Nakashima, and M. Katsura, Temperature dependence of reflectance spectra and color values of hematite by in situ high temperature visible microspectroscopy, Am. Miner., 94, 90-97, 2009.

Zolensky, M., R. Barrett, and L. Browning, Mineralogy and compositional of matrix and chondrule rims in carbonaceous chondrites, Geochim. Cosmochim. Acta, 57, 3123-3148, 1993.

A. Suzuki (e-mail: akiko.s@ess.sci.osaka-u.ac.jp), Y. Yamanoi, T. Nakamura, and S. Nakashima 